\section{ARTIGO}

Recebido em:

$31 / 01 / 2013$

Aceito em: 05/06/2013

\title{
Pesquisas sobre biblioteca escolar no Brasil: o estado da arte
} Research on school library in Brazil: state of the art

\author{
Bernadete CAMPELLO ${ }^{1}$ \\ Paulo da Terra CALDEIRA ${ }^{2}$ \\ Adriana Bogliolo Sirihal DUARTE ${ }^{3}$ \\ Carlos Alberto Ávila ARAÚJO 4 \\ Maria da Conceição CARVALHO ${ }^{5}$ \\ Mara Eliane Fonseca RODRIGUES 6 \\ Laura Valladares de Oliveira SOARES7
}

\section{RESUMO}

O objetivo deste estudo foi o estabelecimento do estado da arte da pesquisa sobre biblioteca escolar no Brasil, entre 1975 e 2011, buscando identificar: assuntos pesquisados; embasamento teóricoconceitual; metodologias e técnicas utilizadas; resultados e conclusões dos estudos. A metodologia foi análise documental de setenta relatos de pesquisa sobre o tema, separados em seis categorias: biblioteca escolar como espaço de aprendizagem, interação bibliotecário/professor, estudos de usos e usuários, coleção, leitura e pesquisa escolar. Os resultados revelaram que existe consciência da necessidade de se garantir o espaço da biblioteca na escola, considerando-se que ela pode contribuir para a aprendizagem. Há mais estudos na categoria leitura, e tendência no aumento da categoria pesquisa escolar. A necessidade de trabalho conjunto professor/bibliotecário foi reafirmada. Os estudos de uso e usuários ainda estão presos a abordagem tradicional, não conseguindo realizar um diálogo efetivo com a questão pedagógica. As metodologias dos estudos analisados foram em sua maioria qualitativas e o referencial teórico apresentou fragilidade, resultante da pouca clareza de seu uso.

PALAVRAS-CHAVE: Biblioteca escolar. Pesquisas em biblioteca escolar. Interação bibliotecário/professor. Estudos de usos e usuários. Biblioteca escolar - leitura.

v. 18, n. 37, 2013.

p. $123-156$

ISSN 1518-2924

${ }^{1}$ Universidade Federal de Minas Gerais - bscampello@gmail.com

${ }^{2}$ Universidade Federal de Minas - paulodaterra@gmail.com

3 Universidade Federal de Minas - bogliolo@eci.ufmg.br

${ }^{4}$ Universidade Federal de Minas - casal@eci.ufmg.br

${ }^{5}$ Universidade Federal de Minas - mccarv@eci.ufmg.br

${ }^{6}$ Universidade Federal Fluminense - maraeliane121@gmail.com

${ }^{7}$ Universidade Federal de Minas - laurinhavalladaresbr@gmail.com 


\begin{abstract}
The present study aimed to establish the state-of-the-art of the research on school library in Brazil, between 1975 and 2011, trying to identify: its subjects, theoretical foundations, methodology, results and conclusions. A documentary analysis was made, using seventy research reports on school library, divided into six categories of analysis: the school library as a learning space, integration of teacher/librarian, user studies, collection, reading and inquiry learning. The results revealed that exist an awareness of the need to secure the space of the library in the school, considering that it can contribute to the learning process. There is a bigger number of studies in the subject of reading, although there seems to be a trend in the increasing of inquiry learning topic. The studies on teacher/librarian collaboration reaffirmed the need of teacher/ librarian collaboration. User studies are still stuck with a traditional approach, failing to perform an effective dialogue with pedagogical issues. The methodologies of the studies were mostly qualitative and the theoretical foundations were weak, resulting from the lack of clarity of its use.
\end{abstract}

KEYWORDS: School library. Research on school library. Teacher/librarian collaboration. User studies. School library - Reading.

\title{
1 INTRODUCÃo
}

A pesquisa acadêmica na área de Biblioteconomia no Brasil teve início na década de 1970, quando começaram a ser criados os cursos de pós-graduação no nível de mestrado (BRAMBILLA, 2007; GOMES, 2003). Os doutorados começaram a ser implantados na década de 1990, quando a maioria dos programas, que tiveram início como cursos de Biblioteconomia, já haviam mudado para Ciência da Informação. Mesmo com essa nova denominação, a maioria dos programas continuou a acolher projetos sobre temas bibliotecários, entre eles a biblioteca escolar. A primeira dissertação de mestrado e a primeira tese de doutorado tratando da biblioteca escolar foram, entretanto, defendidas na área de educação8.

\footnotetext{
${ }^{8}$ ANNES, Maria Ruth Barros. Biblioteca escolar: centro de recursos a serviço da educação na escola de Io grau. 1975. 189 f. Dissertação (Mestrado em Educação) - Pontifícia Universidade Católica do Rio Grande do Sul, Porto Alegre, 1975.MAGALHÃES, M. H. A. Uma leitura ...da leitura na escola de primeiro grau. 1992.196 f. Tese (Doutorado em Educação) - Faculdade de Educação, Universidade de São Paulo, São Paulo, 1992.
} 
Ao longo dos 40 anos de existência da pós-graduação em Biblioteconomia/Ciência da Informação no Brasil, alguns levantamentos esporádicos revelam que, em termos numéricos, a produção de dissertações e teses sobre biblioteca escolar não foi significativa. No período de 1975 a 1998, Neves (2000) identificou 14 teses e dissertações sobre o tema, entre as 556 defendidas em cursos de mestrado e doutorado em biblioteconomia, ciência da informação e documentação, representando apenas 2,50\% do total. Na verdade, essa exiguidade existe no tema biblioteca em geral, e foi observada por Araújo, Tenório e Farias (2003, p.14) que, estudando temáticas presentes nas 24 dissertações defendidas no Curso de Mestrado em Ciência da Informação da Universidade Federal da Paraíba, no período de 1997 a 2001, descobriram que apenas $13,5 \%$ tratavam do tema biblioteca(escolar, universitária, virtual), entre os outros onze temas identificados.

Para estudar citações presentes em teses e dissertações brasileiras sobre biblioteca escolar, Campello et al. (2007, p. 229) utilizando a base de dados bibliográfica Literatura em Biblioteca Escolar - LIBES ${ }^{9}$, identificaram 35 desses documentos, defendidos entre 1975 a 2002. Na conclusão desse estudo, os autores afirmaram que, "embora tenha havido um aumento da produção nos anos de 1997 e 1998, este é um fato episódico, levando-se a concluir que o tema [biblioteca escolar] esteve pouco presente nas linhas de pesquisa da pósgraduação", confirmando-se a "exiguidade da produção científica da área de biblioteca escolar no Brasil" (CAMPELLO et al., 2007, p. 235).

Alguns dados quantitativos esparsos existem a respeito da produção científica sobre biblioteca escolar no Brasil, que incluem não só teses e dissertações. No estudo de citações acima mencionado (CAMPELLO et al., 2007, p. 228), foram identificados, em junho de 2006, 39 relatos de pesquisa, num total de 332 referências. 0 número de pesquisas publicadas subiu para $91 \mathrm{em}$ 2011.

\footnotetext{
${ }^{9}$ Literatura em Biblioteca Escolar - LIBES, que inclui artigos de periódicos, dissertações, teses e trabalhos apresentados em eventos sobre o tema publicados no Brasil desde a década de 1960. http://gebe.eci.ufmg.br/index.php?option=com_content\&view=article\&id=49\&Itemid $=40>$.
} 
No nível internacional, a situação não é diferente. Na introdução de um número especial da revista Library Trends sobre biblioteca escolar, Mardis (2009, p. 1) lamenta que a área de biblioteca escolar conte apenas com dois periódicos arbitrados: School Library Media Research ${ }^{10}$ e SchoolLibrariesWorldwide ${ }^{11}$, esclarecendo que, além disso, artigos de pesquisa sobre o tema aparecem com pouca frequência em periódicos da área de Biblioteconomia/Ciência da Informação em geral. Entretanto, não comparando com outras áreas, há evidências de que a pesquisa sobre biblioteca escolar está em expansão no âmbito internacional. Na década de 2000, as editoras de SchoolLibrariesWorldwiderealizaram dois estudos (CLYDE e OBERG, 2004, p. 4; OBERG, 2006, p. iii) para verificar se o número de artigos de pesquisa publicados na revista estava aumentando. Comparando a quantidade desses artigos com outros tipos de trabalhos publicados, os estudos revelaram que, ao final de 2003, a porcentagem de artigos de pesquisa era de $51,2 \%$, enquanto que ao final de 2006 havia aumentado para 58,0\%.

Há, portanto, um corpo de conhecimentos em expansão sobre biblioteca escolar que pode ajudar a entender melhor as questões que envolvem o tema e a sustentar uma prática baseada em evidências, levando a ações mais consistentes e duradouras. É necessário, conhecer melhor as pesquisas já realizadas sobre o tema, de forma a estabelecer o estado da arte deste corpo de conhecimentos no que diz respeito à produção científica brasileira sobre biblioteca escolar. Este esforço de ordenamento pode ser o primeiro passo para que se realize o que, em 1998, Elizabeth Martucci propunha no texto Rompendo o silêncio: a biblioteca escolar e a trajetória de um pesquisador, apresentado no 1ํㅗㄹ Seminário Biblioteca Escolar Espaço de Ação Pedagógica: "Por fim, fica o desejo e a recomendação de que os pesquisadores envolvidos com a temática unam esforços para uma ação

\footnotetext{
${ }^{10}$ School Library Media Research, atualmente com o título School Library Research, é publicado pela American AssociationofSchoolLibrarians (AASL), divisão de bibliotecas escolares da American Library Association (ALA). <http://www.ala.org/aasl/slr>

${ }^{11}$ SchoolLibrariesWorldwide é uma publicação semestral da InternationalAssociationofSchoolLibrarianship (IASL), divulgando resultados de pesquisas realizadas em vários países sobre biblioteca escolar e temas relacionados. <http://www.iaslonline.org/pubs/slw/index.htm>
} 
mais integrada e coletiva de trabalho, para o que já me considero participante do pretenso processo de construção" (MARTUCCI, 1999, p. 38).

\section{OBJETIVOS}

0 presente estudo teve como objetivo estabelecer o estado-da-arte da pesquisa sobre biblioteca escolar no Brasil. Como objetivos específicos pretenderam-se identificar:

1. As categorias de assuntos pesquisados dentro do tema biblioteca escolar;

2. O embasamento teórico-conceitual das pesquisas;

3. As metodologias e técnicas utilizadas;

4. Os resultados e as conclusões dos estudos.

A análise desses dados permitirá a elaboração de uma síntese do conhecimento sobre biblioteca escolar, possibilitando perceber suas características, sua relação com o conhecimento da área como um todo e as tendências que marcam seu desenvolvimento.

\section{METODOLOGIA}

O presente estudo consistiu em uma análise documental de relatos de pesquisa sobre biblioteca escolar existentes na literatura publicada no Brasil sobre biblioteca escolar, excluindo-se dezoito diagnósticos sobre a situação de bibliotecas escolares, cuja análise foi feita em estudo à parte (CAMPELLO et al, 2012). Noventa e um relatos foram identificados por meio da base de dados LIBES ${ }^{12}$, entre teses, dissertações, artigos de periódicos e trabalhos de eventos, cobrindo textos de 1975 até 2011.

\footnotetext{
${ }^{12}$ A LIBES é uma base de dados que busca reunir, de forma o mais exaustiva possível, referências e resumos de documentos (alguns em texto completo) sobre biblioteca escolar produzidos no Brasil. Inclui livros, artigos de periódicos, dissertações, teses e trabalhos apresentados em eventos, publicados a partir da década de 1960. A Biblioteca Etelvina Lima, da Escola de Ciência da Informação da UFMG, é a responsável pela atualização da base, que é alimentada sistematicamente com material do próprio acervo da Biblioteca e através de contribuições de pesquisadores e de profissionais da área.
} 
Desses, foram localizados e obtidos em texto completo 70 relatos que formaram o corpus documental do presente estudo. Os critérios usados para caracterizar esses 70 relatos foram aqueles definidos por Pálsdóttir, et al. (1997, citado por CLYDE e OBERG, 2004, p. 2), que consideram relatos de pesquisa textos que apresentem:

- Evidência de que o trabalho relatado foi concebido como pesquisa;

- Declaração de objetivos, ou de hipóteses, ou de questões de pesquisa;

- Informações sobre a metodologia de pesquisa utilizada;

- Discussão dos resultados da investigação;

- Inserção no contexto de pesquisas relacionadas;

- Discussão sobre as implicações do trabalho;

- Lista de referências.

Uma leitura dos elementos paratextuais dos 70 documentos que atenderam aos critérios acima permitiu sua categorização em seis assuntos, dentro do tema geral biblioteca escolar. A definição dessas categorias levou em consideração a necessidade de acomodar todos os documentos a serem analisados, tendo sido as categorias modeladas num nível de especificidade que garantisse a não fragmentação da análise. As seis categorias ficaram assim definidas:

1. biblioteca escolar como espaço de aprendizagem: 11 estudos

2. integração professor/bibliotecário: 08 estudos

3. estudos de usos e usuários: 13 estudos

4. coleção: 06 estudos

5. leitura: 17 estudos

6. pesquisa escolar:15 estudos

Alguns estudos poderiam ter sido incluídos em mais de uma categoria. Entretanto, optou-se por colocá-los naquela que representasse o tema mais relacionado.

\section{ANÁLISE}

A seguir apresenta-se a análise de cada categoria individualmente, 
elaborando-se nas considerações finais a síntese que possibilitará revelar o estadoda-arte da pesquisa sobre biblioteca escolar no Brasil.

\subsection{Categoria: A biblioteca escolar como espaço de aprendizagem (11 estudos)}

As onze pesquisas nesta categoria consistem de cinco dissertações, quatro teses e dois trabalhos de eventos e abarcam um período de 36 anos (de 1975 a 2010). Têm como característica comum o fato de focalizarem a biblioteca na sua perspectiva educativa, preocupando-se em clarear a contribuição que ela pode dar à aprendizagem, partindo do pressuposto de que a biblioteca é pouco reconhecida e pouco utilizada pela comunidade educacional, e em mostrar que essa contribuição pode e deve ocorrer de maneira efetiva. Abordando a questão em perspectiva ampla ou específica, os autores, embora enfatizando deficiências bem conhecidas das bibliotecas escolares brasileiras, demonstram acreditar na sua potencialidade para ajudar na aprendizagem.

Sete estudos focalizaram a função educativa da biblioteca escolar de forma abrangente, traçando um panorama de como ela funciona - ou poderia funcionar como espaço de aprendizagem. As outras quatro abordaram questões específicas, enfatizando elementos que têm possibilidade de influenciar nas práticas educativas na biblioteca escolar e discutindo de que maneira a biblioteca lida, ou deverá lidar, com: a introdução da informática, a obrigatoriedade do ensino de história e cultura afro-brasileira e africana nas escolas, a educação de jovens e adultos e os estímulos que documentos de políticas públicas educacionais oferecem para ampliar a função educativa da biblioteca escolar.

O referencial teórico dos estudos constou de revisão de literatura principalmente sobre o conceito de biblioteca escolar. Oito estudos abordaram esse tema explorando-o de diferentes perspectivas: a biblioteca na educação, relação biblioteca e escola, atores e elementos envolvidos no contexto da biblioteca escolar, projetos de biblioteca escolar, biblioteca escolar como espaço da construção e disseminação do saber, relação entre biblioteca, informação e cidadania, biblioteca escolar como lócus de cultura e informação. 0 bibliotecário também foi tema das revisões de literatura, analisando-se suas funções e seu papel como educador. Outros 
temas abordados foram: paradigmas de conservação, difusão e disseminação da informação, contexto sociocultural da informação na contemporaneidade, busca de informação, pesquisa, dispositivos, educação para a informação, letramento informacional, leitura, cidadania/universalismo/multiculturalismo, políticas públicas e marcos legais para educação antirracista no Brasil e a lei 10639 no contexto das bibliotecas. Quatro estudos explicitaram a finalidade para a qual utilizaram os conceitos que compuseram o referencial teórico, sendo a maioria usada para análise dos dados.

No que diz respeito à metodologia, em três pesquisas foi feita intervenção direta na realidade, quando as pesquisadoras trabalharam com a comunidade no planejamento e na implantação de sua biblioteca escolar, utilizando metodologias que chamaram de "pesquisa ação", "pesquisa participante" e "pesquisa cooperativa". As outras foram na maioria pesquisas qualitativas, com análise descritiva. Poucas apresentaram dados quantitativos e nessas os resultados apareceram apenas em forma de porcentagens. Um estudo, que trabalhou com uma amostra de 53 escolas e 76 responsáveis por bibliotecas, realizou teste de hipótese para verificar diferenças entre áreas geográficas, usando a Análise de Variância de Friedman (ANOVA). Os objetos empíricos variaram entre: escolas públicas (10 11 estudos) e escolas privadas (3), e os sujeitos estavam entre as seguintes categorias: professores/equipe pedagógica (6 estudos), alunos (4), bibliotecários (2), responsáveis pelas bibliotecas (2). Outra fonte de dados foram os documentos de origem acadêmica, governamental e institucional, usados em cinco pesquisas. Ressalta-se que em sete estudos foram utilizados de dois a três instrumentos de coleta de dados, incluindo entrevistas (5 estudos), questionários (5), fontes documentais (4), observação (3) e grupo focal (1 estudo). A análise ajudou a compor o retrato da biblioteca escolar que, na visão dos pesquisadores, deve e pode contribuir para melhorar a qualidade da educação brasileira.

As conclusões podem ser agrupadas em duas perspectivas opostas: uma que confirma problemas que têm afetado a biblioteca escolar e que dificultam sua atuação como espaço de aprendizagem; outra que revela possibilidades de atuação efetiva da biblioteca escolar como espaço de ação pedagógica.

No seu conjunto, as onze pesquisas desta categoria, sem ignorar dificuldades 
estruturais, apresentaram um panorama extremamente rico, conjugando elementos teóricos aos dados da realidade das bibliotecas escolares brasileiras, possibilitando conhecer melhor seu potencial como espaço de aprendizagem e entrever caminhos para interferir nessa realidade.

\subsection{Categoria: integração bibliotecário/professor (8 estudos)}

Os estudos analisados nesta categoria verificaram o trabalho colaborativo entre professor e bibliotecário, principalmente com vistas a apontar como cada um percebe o trabalho do outro e como ambos trabalham (ou têm potencial para trabalhar) em conjunto, compreendendo a função educativa da biblioteca escolar. Foram analisados oito relatos de pesquisa, publicados no período de 1984 a 2011 (compreendendo 28 anos), sendo seis dissertações de mestrado (5 em Programas de Pós-Graduação em Biblioteconomia ou em Ciência da Informação e um em Programa de Pós-Graduação em Educação), um artigo de periódico e um trabalho de evento.

A revisão de literatura de todos eles foi comum em demonstrar que, embora muito se conheça na teoria sobre o potencial educativo do trabalho conjunto desses dois profissionais para a formação do educando (tanto no que concerne à formação do leitor quanto ao papel da pesquisa escolar) a prática no Brasil não tem revelado o relacionamento entre esses profissionais.

Dois dos trabalhos analisados optaram por avaliar a formação dos profissionais, sejam educadores, sejam bibliotecários, a fim de verificar se em sua formação acadêmica eles estavam sendo preparados para a atuação conjunta e para que cada um perceba o papel do outro. Vários pontos em comum podem ser ressaltados nessas duas pesquisas, entre eles a preocupação com a formação dos profissionais que deveriam trabalhar em conjunto na escola - professor e bibliotecário - e os resultados que apontaram que essa formação não os prepara para o trabalho conjunto.

No outro extremo, há os trabalhos que, ao invés de investigar se os professores estavam sendo preparados, em sua formação acadêmica, para trabalhar em conjunto com os bibliotecários e fazer da biblioteca espaço de aprendizagem (e vice-versa, se os bibliotecários estavam sendo preparados para o trabalho articulado com as atividades de ensino), verificaram como estava se dando a prática dos 
profissionais - bibliotecários e professores - na formação do educando. Nessas pesquisas foram realizadas entrevistas ou aplicados questionários com professores das escolas, verificando sua atuação e sua percepção da biblioteca e do bibliotecário, ou entrevistas com bibliotecários, para avaliar sua percepção de seu papel educativo e de parceria com a equipe pedagógica.

Tomando como referência os níveis de colaboração entre bibliotecário e equipe pedagógica estabelecidos por Montiel-Overall (2005), a saber, coordenação, cooperação, instrução integrada e currículo integrado, o que todos os trabalhos analisados concluíram foi que a interação entre bibliotecários e professores nos universos pesquisados dava-se de forma tímida, restringindo-se aos dois primeiros níveis de colaboração: coordenação e, em poucos casos de sucesso, cooperação. As análises dos dados demonstram que as duas categorias profissionais apresentavam dificuldade em estabelecer boas relações de parceria no desenvolvimento de atividades pedagógicas, de leitura ou de pesquisa escolar.

Os bibliotecários descreveram o que já havia sido percebido pelas duas pesquisas acima relatadas: que o curso de graduação em Biblioteconomia era insuficiente para consolidar essa interação, por não apresentar, em sua grade curricular, disciplinas que a subsidiassem. Afirmaram, ainda, que raramente eram procurados por professores para contribuir em alguma atividade didática.

A grande maioria dos professores considerou a biblioteca muito importante, mas poucas vezes efetivamente a consultavam. Como fatores que os impediam de frequentá-la com maior intensidade estavam os já conhecidos: desinteresse, desconhecimento do acervo, cansaço diário, falta de motivação e, principalmente, falta de tempo.

Os resultados destas pesquisas demonstram que o trabalho realmente integrado entre professor e bibliotecário raramente ocorria. 0 número de bibliotecários escolares parece ser insuficiente para a promoção desse tipo de trabalho e, embora houvesse percepção por parte dos professores da importância de levar o estudante à biblioteca, por fatores diversos, isso raramente se efetivava.

Finalmente, uma pesquisa analisou a produção científica sobre a integração bibliotecário/professor no contexto educacional brasileiro. Tomou como corpus de análise um total de 96 documentos (no período de 1927 a 1991) das áreas de 
biblioteconomia, educação ou geral, que permitiram, direta ou indiretamente, avaliar a integração bibliotecário - professor, não só no âmbito da biblioteca escolar, mas também da biblioteca universitária. Concluiu que a produção sobre o assunto não é muito aprofundada. A integração entre esses profissionais é muito proclamada como necessária, mas pouco efetivada tanto por bibliotecários quanto por professores. Mais uma vez, explicita-se o fato de que a integração não tem eco nos cursos de formação do bibliotecário, a quem a iniciativa para a realização de um trabalho integrado é delegada. Nos poucos casos de sucesso, o maior benefício percebido do trabalho integrado é na formação dos hábitos de leitura.

Portanto, as pesquisas avaliadas usam como aporte metodológico a realização de questionários, entrevistas e análise documental. Independentemente do método utilizado as principais conclusões explicitam a importância percebida, mas a pouca efetivação do trabalho integrado entre bibliotecário e professor, tendo como principais motivos a falta de preparo, durante sua formação, dos profissionais (bibliotecário e professor) para o desenvolvimento de um trabalho conjunto; e a falta de condições de trabalho (dupla jornada dos professores, bibliotecas sem bibliotecários, multiplicidade de atribuições, falta de tempo, etc.) para implementação desta prática.

\subsection{Categoria: Estudos de usos e usuários (13 estudos)}

A categoria estudos de usos e usuários é composta por treze relatos, assim distribuídos: oito trabalhos apresentados em eventos, dois artigos de periódicos e três dissertações de mestrado, cobrindo um período de 29 anos (1982 a 2010).

São trabalhos dedicados ao estudo de realidades empíricas de diferentes tipos de bibliotecas escolares (públicas, comunitárias, de colégios confessional e militar) e voltados também para públicos específicos (alunos de ensino médio e/ou fundamental, supletivos), de diversas partes do Brasil (Belo Horizonte, Porto Alegre, Campo Grande, Rondonópolis, entre outras). Alguns estudos comparam realidades de bibliotecas diferentes, a partir da eleição de uma característica específica.

Apesar da diversidade de objetos empíricos, do ponto de vista do referencial teórico, tais estudos são, em sua maioria, ancorados na chamada abordagem tradicional de estudos de usuários (DERVIN; NILAN, 1986; FERREIRA, 1995): 
priorizando métodos quantitativos de coleta de dados (principalmente questionários), voltam-se para o estabelecimento de perfis sócio demográficos dos públicos estudados e para a correlação entre dados desses perfis e indicadores de uso da informação e de aspectos do comportamento informacional (fontes mais utilizadas, serviços mais acessados, frequência de uso, grau de satisfação, barreiras encontradas, entre outros).

Afastam-se desse modelo alguns poucos estudos, notadamente aqueles identificados com a chamada abordagem alternativa (DERVIN; NILAN, 1986; FERREIRA, 1995) de estudos de usuários, de natureza cognitiva, destacando-se, nesse caso, a utilização da abordagem baseada em processo proposta por Kuhlthau (2004).

Entre as conclusões mais comumente encontradas nos trabalhos analisados, destaca-se o alto grau de satisfação com a biblioteca, embora não seja problematizado o grau de exigência ou os critérios de avaliação utilizados pelos alunos. Os principais problemas encontrados são, invariavelmente, a falta de investimentos, o acervo desatualizado, o espaço físico inadequado e a carência de computadores. As questões relacionadas com os desafios da atuação da biblioteca escolar nunca são colocadas no profissional da informação - é sempre aceito como ponto evidente, sem necessidade de demonstração, que a simples presença do profissional é elemento que garante a qualidade, e sua ausência é, necessariamente, a fonte dos problemas. A dimensão pedagógica da biblioteca também é muito pouco problematizada nesses estudos. Na maior parte das vezes, apenas se identifica o fato de a biblioteca funcionar como local de castigo ou ser conduzida por professores afastados da sala de aula por motivos médicos.

O maior vínculo com a questão educacional presente nesses estudos se dá com a constatação da precariedade da biblioteca, e a aproximação dessa realidade com a realidade do setor de educação como um todo no país. Em alguns trabalhos, há uma discussão sobre métodos tradicionais de ensino e novas propostas pedagógicas, a partir da ideia de que o aluno deve ser sujeito do processo de aprendizagem. Em outros, aparecem propostas na linha de animação cultural, contação de histórias, a biblioteca como lugar de despertar o gosto pela leitura. Mas, tanto num caso como noutro, sempre numa linha propositiva e isenta de contradições. Em outros 
trabalhos, é discutida a questão da cidadania, a ligação da biblioteca escolar com a comunidade, seu papel como lugar de encontro. Em menor número, aparecem discussões sobre a natureza da pesquisa escolar e competência informacional.

A especificidade da biblioteca escolar é, pois, muito pouco revelada. Os trabalhos analisados se parecem, de fato, bastante com os demais estudos de usos e usuários realizados em outros ambientes, como o científico, o administrativo, o empresarial, o institucional, o comunitário, o governamental, entre outros. Alguma especificidade aparece quando se discute a relação docente/discente, gerando uma categorização de dois tipos de usuários de uma maneira bastante marcada.

Outros estudos são muito voltados para o diagnóstico de uso de informação para favorecer a atividade de planejamento de bibliotecas, o que constitui outra característica chave dos estudos da abordagem tradicional de usos e usuários da informação.

Aparece ainda uma certa tensão entre a ideia de biblioteca como espaço físico para o estudo e como recurso efetivo de informação. Nesse sentido, aliás, a internet se apresenta nos estudos, de forma geral, como se fosse uma caixa preta, um novo elemento sobre o qual pouco se sabe - o que se explica também pela época em que os estudos foram realizados. Há um trabalho que realiza um diagnóstico detalhado de seu uso e de seus recursos. Nos dois casos, contudo, as conclusões apontam que a escola ainda não conseguiu incorporá-la como ferramenta de aprendizagem.

Assim, pode-se dizer que pouco se avançou, no campo dos estudos de usos e usuários de biblioteca escolar, no entendimento do significado da biblioteca escolar e das práticas informacionais dos alunos relacionadas com as atividades pedagógicas. Existe, na literatura analisada, com poucas exceções, certo divórcio entre as diretrizes e competências advindas da discussão especificamente biblioteconômica/informacional, de um lado, e as práticas pedagógicas, de outro.

\subsection{Categoria: Coleção (6 relatos)}

Na categoria coleção foram analisados seis estudos, cobrindo um período de 24 anos (1988 a 2004), sendo quatro artigos de periódico, um trabalho apresentado em evento e uma dissertação. 0 foco de todos os estudos foi a coleção da biblioteca. Quatro se propuseram a avaliá-las, seja na perspectiva qualitativa quanto qualitativa, 
englobando aspectos diversos, tais como: atualização, adequação, utilização, quantidade de materiais, composição em termos de suportes, responsabilidade pela seleção. Os objetos empíricos foram acervos de bibliotecas de escolas públicas principalmente; apenas um desses estudos incluiu escolas privadas. Esses quatro estudos avaliaram, no total, acervos de 93 bibliotecas, localizadas em três cidades: Belo Horizonte (MG), Marília (SP) e Porto Alegre (RS). Como informantes, predominaram os bibliotecários e/ou responsáveis pelas bibliotecas, sendo que apenas um estudo coletou dados por meio de alunos e professores.

Dois estudos analisaram aspectos que influenciam o perfil da coleção. 0 primeiro estudou a produção editorial brasileira para o ensino fundamental, tendo como objeto empírico 91 organizações produtoras. Os dados foram obtidos por meio de questionários, e os resultados permitiram concluir que esse segmento da indústria editorial tinha produção diversificada, oferecendo uma variedade de materiais, como $C D$-ROMs, fitas cassete, disquetes, vídeos e material geográfico, além do livro impresso. Nesse estudo, foram também analisados os catálogos das editoras que, embora com boa aparência externa, apresentavam deficiências nas informações, revelando pouca preocupação em fornecer dados para ajudar as bibliotecas a selecionar os materiais.

0 segundo estudo analisou as diretrizes curriculares nacionais para a educação infantil e o ensino fundamental ${ }^{13}$, a fim de delinear o perfil da coleção de uma biblioteca escolar alinhada com as metodologias de aprendizagem propostas no documento, concluindo que ela exige coleção que contemple a diversidade textual.

Os resultados mais significativos dos quatro estudos que avaliaram coleções podem ser assim resumidos:

- dois estudos que verificaram a média de materiais por aluno encontraram números bastante próximos (3,56 livros por aluno e 3,6 volumes por aluno), mas que não permitem comparação devido à diversidade das formas de coleta dos dados;

- quanto à composição foram encontrados acervos sobrecarregados com materiais inapropriados, como livros didáticos e do acervo de classe; predominância de materiais tradicionais e impressos; as diferenças entre as coleções das bibliotecas

\footnotetext{
${ }^{13}$ Foram analisados nesse estudo os Parâmetros Curriculares Nacionais e o Referencial Curricular Nacional para a Educação Infantil, do MEC.
} 
ocorriam em relação aos materiais especiais, indicando que a incorporação desses recursos ocorria em diferentes níveis, sendo que algumas apresentavam características de centros multimeios.

- quanto à responsabilidade pela seleção: o bibliotecário pouco participava, sendo o processo de formação do acervo feito fora da biblioteca, em geral por professores, orientadores, supervisores e diretores. Os bibliotecários tinham pouco conhecimento da proposta pedagógica da escola e não participavam de reuniões de decisão; faziam pouco uso de resenhas, como instrumentos de seleção; não haviam diretrizes explícitas que direcionassem o desenvolvimento das coleções e nem comissão que legitimasse o processo.

Outras conclusões foram: escassez de computadores com acesso à internet para uso de alunos, prática de encaminhamento do aluno para outras bibliotecas sem acordos cooperativos prévios. A atualização ou idade da coleção foi medida em dois estudos: em um por meio da opinião dos responsáveis pelas bibliotecas e em outro pela consulta aos livros de registro das bibliotecas. Em ambos os casos, dada a falta de parâmetros, os resultados foram pouco significativos.

A metodologia variou em função dos objetivos propostos. Três estudos utilizaram análise documental descritiva, apresentando os resultados por categorias. Os quatro que estudaram especificamente as coleções usaram metodologias mistas (quantitativas e/ou qualitativas), apresentando os resultados por meio de porcentagens e descrições, respectivamente. 0 instrumento mais utilizado para coleta de dados foi o questionário, complementado em dois estudos com entrevistas e em um com observação.

O referencial teórico que orientou os estudos, e que apareceu como revisão de literatura, foi o conceito de biblioteca como parte integrante da escola, espaço de ação pedagógica, que propicia aprendizagem permanente, questionadora, crítica, com significado e centrada no estudante, privilegiando a construção do conhecimento pelo aluno. A biblioteca escolar é o lugar de formação de leitores e de atitude científica, onde se aprendem habilidades de acessar e de interpretar informação, e para isso, é necessária uma coleção adequada, com recursos informacionais variados e abundantes, que dê suporte às atividades curriculares.

Embora em pequeno número, os estudos desta categoria (Coleção), não 
deixaram de apresentar uma quantidade significativa de recomendações que tinham como foco o aperfeiçoamento das coleções das bibliotecas escolares. Nesse sentido foram sugeridas diversas ações: aumento quantitativo dos acervos; integração da internet ao acervo, com a seleção de sites de boa qualidade; avaliações criteriosas dos materiais pelos bibliotecários, que contribuam para o aperfeiçoamento da qualidade desses materiais; trabalho integrado de bibliotecário e professores para adequar o acervo aos conteúdos escolares; elaboração de política de formação e desenvolvimento de acervo de acordo com o projeto pedagógico da escola; criação de espaços diversificados na biblioteca para acolher a variedade de suportes; formação do bibliotecário, que lhe dê condições de atuar com mais segurança na formação do acervo; conscientização dos editores, para que produzam material de divulgação que possibilite a seleção criteriosa dos livros e outros recursos informacionais.

Uma característica que emerge dos estudos desta categoria é a diversidade de objetivos a que se propuseram: todos buscaram entender mais de um aspecto relativo à coleção. Assim, alguns poderiam ser categorizados também como estudos de usuário, por abordarem o uso dos materiais, outros, como diagnósticos, por levantarem dados quantitativos a respeito das condições gerais de funcionamento das bibliotecas. Há, portanto, uma dispersão de dados, difíceis de serem comparados, considerando-se não só a variedade de objetivos propostos como também a diversidade de foco na coleta de dados. Por exemplo, apenas um estudo fez uso de referencial estabelecido anteriormente por outro autor, mas não de forma a permitir comparações.

\subsection{Categoria: Leitura (17 relatos)}

$\mathrm{Na}$ categoria leitura e formação do leitor foram identificados e analisados 17 trabalhos. São estudos realizados no período de 1980 a 2007, assim distribuídos: dois trabalhos na década de 1980, três trabalhos na década de 1990 e 12 trabalhos de 2000 a 2007, sendo que oito foram realizados como dissertação de mestrado, dois como tese de doutorado e sete trabalhos apresentados em eventos da área de Biblioteconomia.

A temática da leitura, a julgar por essa sequência cronológica, vem atraindo mais a atenção dos pesquisadores acadêmicos, sendo interessante notar que cinco 
dissertações de mestrado e duas teses de doutorado foram defendidas em faculdades de educação, em contraposição a três dissertações defendidas em programas de mestrado de ciência da informação. De fato, a promoção da leitura entre crianças e jovens tal qual vem sendo proposta e realizada no ambiente escolar é uma preocupação que orienta as reflexões daqueles dois campos disciplinares e, como vamos verificar em seguida, além dos alunos do ensino fundamental e médio professores e bibliotecários tem sido, de forma equiparada, objeto de investigação das pesquisas em foco.

O estágio de ensino fundamental, que atinge crianças e pré-adolescentes de seis a 14 anos, tem sido privilegiado como alvo de estudos se comparado ao número menor de trabalhos relacionados ao ensino médio - que atende, regra geral, a adolescentes de 15 a 17 anos. Seria interessante verificar, de forma mais aprofundada, se essa escolha dos pesquisadores corresponde a uma conhecida queixa de professores referente a uma queda do interesse pela leitura quando a criança começa a entrar na puberdade. Os adolescentes, de fato, leem menos do que as crianças? Será que essa ideia preconcebida interfere nas escolhas metodológicas das pesquisas acadêmicas sobre leitura?

No que se refere à definição do objeto, a maior parte dos estudos vai se ater à realidade de uma escola específica, realizando um estudo de caso, enquanto outros tentam alcançar o problema da promoção da leitura numa determinada rede oficial de escolas (Natal-RN e BH-MG).

No amplo espectro de possibilidades de abordagens que a investigação sobre a leitura de crianças e jovens escolares permite, a análise desse conjunto de estudos permite supor que os das décadas de 1980 e 90 estão mais voltados para uma análise diagnóstica da situação da promoção da leitura na escola, tentando detectar se e como a escola trabalha com essa questão, avaliando em bloco se os alunos gostam de ler e se professores e bibliotecários estão preparados para atuar como incentivadores do gosto e da competência pela leitura. 0 resultado dessas pesquisas aponta, grosso modo, para uma grande dificuldade por parte desses últimos em lidar com a questão da leitura, até porque, desvelam ainda que esses pesquisadores, professores e bibliotecários não são, regra geral, eles próprios leitores.

A partir do ano 2000, com a acessibilidade crescente das novas tecnologias de 
informação e comunicação, tanto na vida pessoal dos escolares quanto no trabalho da escola, os pesquisadores vão se voltar para uma outra vertente da problemática da leitura, qual seja, a influência da internet na prática de leitura de adolescentes. Em consequência, a velha e mesma questão do papel da escola como formadora (ou não formadora) de leitores é abordada em alguns trabalhos à luz desse novo elemento, a informação online e a possibilidade de acesso autônomo de crianças e jovens a ela.

No que diz respeito ao referencial teórico desses estudos vejamos primeiro as dissertações e teses defendidas a maioria em Faculdades de Educação e apenas três em Escolas de Ciência da Informação. Contudo, o objetivo de todas elas tem uma variação mínima, qual seja, investigar as práticas de leitura, seja na sala e aula, seja na biblioteca, ora focalizando apenas os alunos ou os professores, ora procurando entender as inter-relações entre a ação dos agentes de leitura - professores e bibliotecários - e o efeito dessa ação sobre os alunos. Na maioria desses trabalhos é possível identificar, em graus de aprofundamento diferenciados, a presença significativa das teorias sócio interacionistas de Bakhtin e Vygotsky, e dos brasileiros João W. Geraldi e Sônia Kramer. Como se sabe, a aprendizagem na perspectiva interacionista resulta do exercício de interação social e compartilhamento de significados socialmente aceitos, dentro do estágio atual e potencial da criança ou adolescente, considerando o aluno inserido numa sociedade e em uma cultura que determina esse conhecimento. Nesse sentido, tanto o professor quanto o bibliotecário são mediadores potenciais da aprendizagem daquilo que o aluno ainda não sabe, a partir de estratégias que envolvem o compartilhamento de ideias para a produção de conhecimento coletivo e desenvolvimento de um sujeito crítico e criativo, capaz de interagir no seu meio social. A vertente sócio histórica da leitura a partir de Bourdieu e Chartier, e também da pesquisadora brasileira Marisa Lajolo é assumida por um dos trabalhos analisados, que persegue o objetivo de identificar as práticas de leitura na escola e na biblioteca levando em consideração não apenas o comportamento do(s) sujeito(s) da leitura como as condições sócio históricas em que ele se insere.

Além dessas duas correntes teóricas, foram também identificados como suporte teórico-metodológico, muitas vezes intercalados com outras teorias: a ideia de letramento tal qual desenvolvida no Brasil por Magda Soares; a estética da 
recepção, de Jauss, segundo a qual o texto literário ou artístico não existe apenas pela criação do artista, mas pela relação estabelecida entre o objeto - o texto - e o receptor ou leitor; a perspectiva da psicologia fenomenológica da leitura trabalhada por Ezequiel T. da Silva que entende a práxis da leitura em termos de constatação, cotejo (ou reflexão) e transformação por parte do leitor ou, em outros termos, de fruição, reflexão e criação; e, ainda, a linha de cognitivistas americanos que focalizam o processo de aquisição do conhecimento tendo como principais fatores os fatos e processos que estão por trás do comportamento (e brasileiros como Ângela Kleiman que pensam a compreensão textual e a leitura como um processo interativo em que o leitor utiliza os diferentes níveis de conhecimento para que ocorra essa interação).

Os instrumentos de coleta de dados na grande maioria dos trabalhos acadêmicos é a observação, o questionário e a entrevista, sendo que um estudo utiliza a elaboração de portfólio pelos professores investigados e outra trabalha com a análise de conteúdo de documentos oficiais relativos à educação do ensino fundamental.

Os trabalhos apresentados em eventos da área de Biblioteconomia e Ciência da Informação apresentam uma grande disparidade no que se refere à profundidade da investigação e embasamento teórico. Enquanto aqueles trabalhos constituídos por extratos de dissertações e teses defendidas em Faculdades de Educação e escolas de Ciência da Informação atendem a requisitos mínimos de qualidade, até pelo fato de já terem passado pelos critérios de julgamento de bancas específicas. Alguns outros trabalhos demonstram uma desconcertante ligeireza na abordagem conceitual e superficialidade na construção metodológica.

Se, por um lado, pode-se pensar, ao término da análise desse conjunto de trabalhos, que a preocupação com a competência leitora nas escolas tem sensibilizado um maior número de pesquisadores tanto da área da Educação quanto da Ciência da Informação, e que termos e conceitos como ressignificação da formação do leitor e o processo de mediação da leitura, encontrados nos textos analisados, apontam para um deslocamento positivo no olhar do pesquisador ao pensar o trabalho com a leitura na escola, por outro lado a permanência dos mesmos resultados encontrados dos anos 1980 até os trabalhos mais recentes mostra que, ainda que haja a apropriação de interessantes teorias por parte de mestres e 
doutores, na vida cotidiana das escolas não houve avanço com o trabalho de formar crianças e adolescentes como leitores competentes e com uma verdadeira motivação para o ato de ler na escola e fora dela. Os resultados revelam, de fato, o insucesso da escola na promoção da leitura informativa e literária, pondo à mostra o despreparo de professores e bibliotecários para esta tarefa. Na melhor das hipóteses, é mostrada uma defasagem entre o discurso dos mediadores sobre a leitura e a prática pedagógica. Uma dissertação defendida em um programa de pós-graduação em Educação por uma bibliotecária chega a afirmar que, sem planejamento adequado, e com agentes de leitura que não leem a escola tem sido um espaço que desenvolve, de forma contraditória, um discurso sobre o valor da leitura ao mesmo tempo em que, nas salas de aula e na biblioteca, se desenvolvem estratégias inibidoras da leitura autônoma e crítica.

\subsection{Categoria: Pesquisa escolar (15 relatos)}

Nesta categoria foram analisados quinze trabalhos que abarcam um período de 22 anos (de 1989 a 2010), sendo oito dissertações, três trabalhos de evento, três artigos de periódico e uma tese. Esses trabalhos tratam de diversos aspectos da pesquisa escolar, revelando a preocupação dos estudiosos com um tema que constitui, ao lado do estímulo à leitura, uma das funções consideradas das mais importantes do bibliotecário que atua em escolas de ensino básico: a orientação da pesquisa escolar.

Os estudos foram realizados em sua maioria no ambiente de bibliotecas escolares (13 estudos), e dois em bibliotecas públicas ${ }^{14}$. As bibliotecas escolares estudadas pertenciam a escolas públicas (34) e particulares (25) ${ }^{15}$.

Com relação aos participantes, os estudos envolveram, em sua maioria, alunos do ensino fundamental (7 estudos), sendo quatro os estudos que investigaram estudantes de ensino médio ${ }^{16}$. Sete focalizaram também o bibliotecário e/ou os auxiliares da biblioteca; desses sete, dois concentraram-se em estudar apenas o bibliotecário. 0 professor apareceu como informante em sete estudos. A quantidade

\footnotetext{
${ }^{14}$ Lembramos que tradicionalmente no Brasil a biblioteca pública tem substituído a biblioteca escolar como espaço de realização de trabalhos escolares.

15 Um estudo não mencionou a filiação institucional da biblioteca onde foi realizado.

16 Um estudo não especificou o nível escolar dos alunos estudados.
} 
de participantes variou, com um estudo incluindo apenas seis informantes (estudantes de $4^{\text {a }}$ série do ensino fundamental), até outro que coletou dados de 1040 informantes, entre alunos (872), professores (146) e atendentes de biblioteca (22). Assim, percebe-se que têm sido ouvidos os principais protagonistas da pesquisa escolar.

Quanto à metodologia, observou-se o uso generalizado de abordagens qualitativas, com análise descritiva dos dados, coletados na sua maioria por meio de questionários e entrevistas. Poucos estudos apresentaram resultados quantitativos, e quando o fizeram usaram apenas porcentagens. A técnica de observação foi usada em quatro estudos, o exame do produto final do processo (o trabalho dos alunos) em três, e um estudo usou análise documental.

Em geral, as investigações buscaram ampliar a compreensão do fenômeno, mas quatro delas trabalharam numa perspectiva aplicada, propondo modelos para o processo de pesquisa escolar, avaliando a eficiência de um roteiro de pesquisa, sugerindo a integração biblioteca, internet e sala de aula para alcançar melhores resultados na aprendizagem.

Os estudos originaram-se na constatação da inabilidade com que o processo era conduzido na escola e/ou na biblioteca e da percepção da ineficiência da pesquisa escolar como estratégia de aprendizagem, sendo sua principal contribuição a confirmação das suposições iniciais, ou seja, a constatação recorrente de inúmeras fragilidades no processo, que persistem mesmo quando a pesquisa escolar é realizada em ambiente virtual, como foi constatado em quatro estudos que focaram especificamente a internet. As conclusões, com relação aos diversos protagonistas (professores, alunos e bibliotecários) podem ser assim sintetizadas.

- Os professores usavam a pesquisa para sanar lacunas da sala de aula, como a falta de tempo para abordar alguns conteúdos. Não forneciam um roteiro e não orientavam os alunos com relação às fontes a serem consultadas. Reconheciam a necessidade de mudar o processo, mas não estavam seguros sobre como agir; recomendavam aos alunos não copiar os textos, mas acabavam aceitando isso como algo inevitável.

- Os alunos quase nunca entendiam o objetivo da tarefa e a encaravam com angústia e ao mesmo tempo com indiferença e pouca seriedade, mas se preocupavam 
com a apresentação física do trabalho que, muitas vezes, não era sequer lido pelo professor. A prática da cópia eram uma constante, e não se modificou com o uso da Internet.

- Os bibliotecários revelaram dificuldades para lidar com a pesquisa, e demonstravam atitude de passividade, limitando-se a localizar material demandado pelos alunos, não tomando conhecimento do conteúdo das disciplinas e não interagindo com os professores. Essa passividade do bibliotecário foi também observada por estudos que investigaram a pesquisa escolar em ambiente virtual. Mais recentemente, utilizando amostra proposital, um estudo verificou que o bibliotecário pode exercer um papel ativo no processo, embora diferente daquele do professor.

Alguns estudos avançaram ao chamar atenção para elementos contextuais que dificultavam o processo de pesquisa escolar - e não apenas para os sujeitos enfatizando que esta estratégia didática não se encontrava formalmente inserida nos projetos político-pedagógicos das escolas, como deveria, e recomendando que a biblioteca e o bibliotecário fossem ali contemplados. A inexistência de programas de educação de usuários que ensinassem o domínio de habilidades de pesquisa foi outro fator dificultador identificado, bem como a constatação de que o desenvolvimento dessas habilidades exigiria o trabalho conjunto de professores e bibliotecários. Um estudo verificou a falta de atenção dos professores aos aspectos afetivos que perpassam as etapas do processo.

No que diz respeito ao embasamento teórico, seis estudos apenas realizaram revisão de literatura, sem deixar claro para quê e como os conceitos foram utilizados. Os temas e conceitos que apareceram com mais frequência nas revisões foram "pesquisa escolar" e "biblioteca escolar", abordados algumas vezes de forma genérica ou em um nível maior de especificidade como: o processo de pesquisa escolar, pesquisa escolar como estratégia de aprendizagem, pesquisa bibliográfica como parte do processo de pesquisa científica, conceitos e funções da biblioteca escolar, biblioteca escolar e sua função na orientação da pesquisa escolar. Outros conceitos presentes nas revisões de literatura foram: leitura como instrumento de pesquisa, resumos, papel do professor, do bibliotecário e do aluno na realização da pesquisa escolar, mediação bibliotecária, informática na educação, internet, tecnologias de 
informação, ensino fundamental como base de formação do indivíduo, biblioteca pública. Um estudo utilizou a revisão da literatura para estabelecer categorias de análise e outra estabeleceu categorias a partir dos dados coletados.

Alguns autores exploram conceitos e noções como pressupostos para o estudo. É o caso daqueles que levaram em consideração o contexto da sociedade da informação, que faz intenso uso das tecnologias da informação; a tecnologia, particularmente a Internet, que modifica o ambiente de aprendizagem na escola. $\mathrm{Ou}$ estudos que entendem que o desafio crítico para as escolas é possibilitar a aprendizagem por meio de uma variedade de fontes de informação, que a biblioteca escolar é estimuladora da prática da pesquisa escolar, a partir da pedagogia de projetos; ou que em toda prática social existe um processo educativo. Outros usaram conceitos e teorias para "compreender o fenômeno", para "desenvolver o problema da pesquisa" ou como "fio condutor". Nesse sentido, apareceram a Teoria da Ação Comunicativa (Habermas), a Teoria Processualista (Norbert Elias) e a Teoria da Construção Social (Berger e Luckmann). Para coleta e análise de dados A Teoria das Representações Sociais (Moscovici) e o Discurso do Sujeito Coletivo foram usados em uma pesquisa e o InformationSearchProcess (Kuhlthau) em duas.

Pode-se dizer que os estudos acima analisados contribuíram para a compreensão mais aprofundada do problema, apontando caminhos para a busca de soluções. A falta de clareza no uso do referencial teórico parece estar sendo superada e pode ajudar na consolidação do conhecimento sobre pesquisa escolar no âmbito da Ciência da Informação, de forma a contribuir com a área de Educação para aperfeiçoar uma estratégia didática de fundamental importância na implementação de estratégias construtivistas nas escolas.

\section{CONSIDERAÇÕES FINAIS}

A análise dos trabalhos identificados traçou um panorama amplo da pesquisa em biblioteca escolar no Brasil, cobrindo um período de 37 anos (entre 1975 e 2011), possibilitando perceber suas características, sua relação com o conhecimento da área como um todo e as tendências que marcam seu desenvolvimento. São 31 dissertações de mestrado, sete teses de doutorado, 22 trabalhos de eventos e 10 
artigos de periódicos.

Sintetizando a análise das seis categorias, pode-se dizer, em primeiro lugar, que existe entre os pesquisadores consciência da necessidade de se garantir o espaço da biblioteca na escola, considerando-se que ela pode contribuir para a aprendizagem.

0 tradicional envolvimento da biblioteca escolar com a leitura reflete na quantidade de estudos desta categoria que é a mais numerosa (17 relatos). Por outro lado, a preocupação em entender melhor a questão da pesquisa escolar, categoria que vem em segundo lugar em número de relatos (15) demonstra que a área está buscando conhecimento para embasar sua ação educativa que se amplia para além da questão da leitura, e incorpora questões ligadas à competência informacional. Observa-se que o último estudo sobre leitura é de 2007, enquanto que o último sobre pesquisa escolar é de 2011, podendo ser isso um sinal de mudança de foco dos pesquisadores. Estudos mais aprofundados precisariam ser feitos para esclarecer esta questão.

Outro aspecto que a análise revelou foi a certeza de que, no desempenho de sua função educativa, o bibliotecário tem que trabalhar com o professor, em consonância com os objetivos da escola.

Os estudos de uso e usuários, embora em número significativo (13), ainda estão presos a uma abordagem tradicional, não conseguindo realizar um diálogo efetivo com a questão pedagógica, essencial na biblioteca escolar.

No que diz respeito à metodologia o uso de abordagens qualitativas em grande parte dos estudos pode representar um esforço dos autores/pesquisadores em se aprofundar "no mundo dos significados", ou seja, melhor entender os motivos, as aspirações, os valores, as atitudes que envolvem o universo da biblioteca escolar. Pois, segundo Minayo (2006), "esse tipo de método [...] além de permitir desvelar processos sociais ainda pouco conhecidos referentes a grupos particulares, propicia a construção de novas abordagens, revisão e criação de novos conceitos e categorias [...]" (MINAYO, 2006, p. 57).

Contudo, o método qualitativo não exclui o método quantitativo. Vimos que também muitas das pesquisas, principalmente as relativas aos estudos de uso e de usuários, valem-se do método quantitativo para criar modelos ou descrever e 
explicar fenômenos. Na verdade, cada um dos dois tipos de método tem seu papel, seu lugar e sua adequação e ambos podem conduzir a resultados importantes sobre a realidade social. Quando feitos em conjunto, os estudos qualitativos e quantitativos "promovem uma mais elaborada e completa construção da realidade, ensejando o desenvolvimento de teorias e de novas técnicas cooperativas" (MINAYO, 2006, p. 76).

Mas, foram poucos os estudos que fizeram essa conjugação. Talvez, seja essa experiência de trabalho que está faltando aos pesquisadores para romper barreiras e ampliar as fronteiras do conhecimento sobre a biblioteca escolar.

O embasamento teórico conceitual de uma pesquisa expressa os pressupostos teóricos que deram sustentação às ideias e à construção dos conceitos básicos utilizados pelos pesquisadores. Nesta análise, a falta de clareza no uso do referencial teórico parece estar sendo superada. Mas, ainda, uma parcela considerável dos estudos não utiliza um referencial teórico definido, representando uma fragilidade teórica.

Sabe-se que o referencial teórico relaciona-se à seleção do significado de cada conceito-chave tratado na pesquisa e deve estar em consonância com a linha de pesquisa e teoria adotadas pelo autor/pesquisador. Por isso, se o autor/pesquisador não explicitar com clareza as teorias relacionadas ao objeto de estudo, a base teóricoconceitual da pesquisa fica comprometida.

O esforço empreendido com a presente análise vai de encontro à observação feita por Gomes (2007) de que
Nos últimos anos, muito esforço de docentes e pesquisadores tem sido dedicado à avaliação de diretrizes e políticas relacionadas à pós- graduação e à pesquisa na área, com o objetivo de coletivizar perspectivas, partilhar caminhos e superar desafios a ela colocados (Gomes, 2007, p. 8).

Consideramos que este foi o primeiro passo para estimular uma ação coletiva mais consistente e mais ampla, no sentido de tender a maior internacionalização e interdisciplinaridade, garantindo que a pesquisa da área esteja comprometida com a qualidade que se espera de trabalhos que possam realmente contribuir para o aperfeiçoamento das bibliotecas escolares no país. Investigações mais detalhadas serão necessárias para refinar a compreensão obtida com o presente estudo e podem aprofundar os aspectos aqui analisados, além de estudos que possibilitem conhecer 
melhor o perfil dos pesquisadores (área de formação, titulação acadêmica, instituição, etc.), as características do financiamento das pesquisas, o padrão de citação e outros.

\section{REFERÊNCIAS}

ANNES, Maria Ruth Barros. Biblioteca escolar: centro de recursos a serviço da educação na escola de Io grau. 189 f. 1975. Dissertação - (Mestrado em Educação). Faculdade de Educação, Pontifícia Universidade Católica do Rio Grande do Sul, Porto Alegre, 1975. ARAUJO, Eliany Alvarenga de; TENÓRIO, Jovana Karla Gomes; FARIAS, Simarle Nobrega de. $A$ produção de conhecimento na Ciência da Informação: análise das dissertações produzidas no curso de mestrado em Ciência da Informação-CMCI/UFPb no período de 1997/2001. In: ENCONTRO NACIONAL DE PESQUISA EM CIÊNCIA DA INFORMAÇÃO, 5., 2003, Belo Horizonte. Anais... Belo Horizonte: ECI/UFMG, 2003. [CD-ROM].

BRAMBILLA, Sônia Domingues Santos; STUMPF, Ida Regina Chittó. Interfaces da informação: tendências temáticas da pós-graduação. In: ENCONTRO NACIONAL DE PESQUISA EM CIÊNCIA DA INFORMAÇÃO, 8., 2007, Salvador. Anais eletrônicos. Salvador: ANCIB, 2007. [CDROM].

CAMPELLO, B. et. al. Situação das bibliotecas escolares no Brasil: o que sabemos? Biblioteca Escolar em Revista, Ribeirão Preto, v. 1, n. 1, p. 1-29, 2012.

CAMPELLO, B. S. et al. Literatura em biblioteca escolar: características de citações de teses e dissertações brasileiras. Transinformação, Campinas, v. 19, n. 3, p. 227-236, 2007. DERVIN, B.; NILAN, M. Information needs and uses. In: WILLIAMS, Martha E. (Ed). Annual Review of Information Science and Technology , v. 21, Chicago , IL: Knowledge Industry Publications, 1986, p.3-33.

FERREIRA, S. M. S. P. Novos paradigmas e novos usuários da informação. Ciência da Informação, Brasília, v. 25, n. 2, p. 217-223, maio/ago., 1995.

GOMES, Maria Yêda Falcão Soares de Filgueiras. A produção científica em Biblioteconomia e Ciência da Informação no Brasil: tendências temáticas e metodológicas. In: ENCONTRO NACIONAL DE PESQUISA EM CIÊNCIA DA INFORMAÇÃO, 5., 2003, Belo Horizonte. Anais... Belo Horizonte: Escola de Ciência da Informação da UFMG, 2003. [CD-ROM]. GOMES, Maria Yêda Falcão Soares de Filgueiras. Perspectivas da Ciência da Informação no Brasil:um estudo através das comunicações apresentadas no VI ENANCIB. In: ENCONTRO NACIONAL DE PESQUISA EM CIÊNCIA DA INFORMAÇÃO, 8., 2007, Salvador. Anais... Salvador: Ancib, 2007. [CD-ROM]. 
KUHLTHAU, Carol C. Seeking meaning: a process approach to library and information services. 2. ed. Westport, Conn.: Libraries Unlimited, 2004. 247 p.

MARDIS, Marcia A. Introduction: a gentle manifesto on the relevance and obscurity of school libraries in LIS research. Library Trends, v. 58, n. 1, p. 1-8, Summer 2009.

MARTUCCI, Elizabeth Márcia. Rompendo o silêncio: a biblioteca escolar e a trajetória de um pesquisador. In: SEMINÁRIO BIBLIOTECA ESCOLAR ESPAÇO DE AÇÃO PEDAGÓGICA, 1., 1998, Belo Horizonte. Anais... Belo Horizonte, 1999. p. 31-38.

MINAYO, Maria Cecília de S. O desafio do conhecimento: pesquisa qualitativa em saúde. 9. ed. rev. e aprim. São Paulo: Hucitec, 2006.

MONTIEL-OVERALL, P.A theoretical understanding of teacher and librarian collaboration (TLC).SchoolLibrariesWorldwide, v. 11, n. 2, p. 24-48, 2005.

NEVES, Iara da Conceição Bitencourt. Pesquisa escolar nas séries iniciais do ensino fundamental: bases para um desempenho interativo entre sala de aula e biblioteca escolar. 2000. 177 f. Tese (Doutorado em Ciência da Informação e Documentação) - Escola de Comunicações e Artes, Universidade de São Paulo, São Paulo, 2000.

OBERG, Dianne. Editorial: School Libraries Worldwide as a source of evidence for evidencebased practice, 1995-2006. School Libraries Worldwide, v. 12. n. 2, p.i-xii, 2006.

OBERG, Dianne; CLYDE, Laurel A. LIS Journals as a source of evidence for evidence-based practice: the case of School Libraries Worldwide. In: IFLA GENERAL CONFERENCE AND COUNCIL, 70., 2004, Buenos Aires. Proceedings. 2004.

PÁLSDÓTTIR, G.; ÁRNADÓTTIR, I.; SVERRISDÓTTIR, I.; BLÖNDAL, R.; CLYDE, L. A. Published research about library and information science in or related to Iceland. Oslo: Novus Forlag, 1997. p. 85-108 (Nordic Yearbook of Library, Information and Documentation Research).

\section{Anexo 1}

\section{Relatos de pesquisa analisados por categoria (ordem alfabética de autor)}

\section{A biblioteca como espaço de aprendizagem (11 relatos)}

AMARO, R. K. O. F. Biblioteca interativa concepção e construção de um serviço de informação em ambiente escolar. 1998. 129 f. Tese (Doutorado) - Escola de Comunicações e Artes, Universidade de São Paulo, São Paulo, 1998. (Área de concentração: Ciência da Informação e Documentação).

ANNES, M. R. B. Biblioteca escolar: centro de recursos a serviço da educação na escola de Io grau. 1975. 189 f. Dissertação (Mestrado em Educação) - Faculdade de Educação, Pontifícia Universidade Católica do Rio Grande do Sul, Porto Alegre, 1975. 
ANTUNES, W. A. Biblioteca escolar no Brasil: reconceituação e busca de sua identidade a partir dos atores do processo ensino-aprendizagem. 1998. 186 f. Tese (Doutorado em Educação) Faculdade de Educação, Universidade de São Paulo, São Paulo, 1998.

CAMPELLO, B. S. Letramento informacional no Brasil: práticas educativas de bibliotecários em escolas de ensino básico. 2009. Tese (Doutorado em Ciência da Informação) - Escola de Ciência da Informação, Universidade Federal de Minas Gerais, Belo Horizonte, 2009.

CAMPELLO, B. S. Possibilities for implementation of information literacy programs in Brazilian school libraries: information skills in the National Curricular Standards. In: ANNUAL

CONFERENCE OF THE INTERNATIONAL ASSOCIATION OF SCHOOL LIBRARIANSHIP, 2006, Lisboa. IASL Reports 2006. Lisboa: IASL, 2006.

FURTADO, C. C. A biblioteca escolar brasileira no sistema educacional da sociedade da informação. 2000. 124 f. Dissertação (Mestrado em Ciência da Informação) - Faculdade de Estudos Sociais Aplicados, Departamento de Ciência da Informação e Documentação, Universidade de Brasília, Brasília, 2000.

NUNES, E. M. R. Cidadania e multiculturalismo: a lei 10.639/03 no contexto das bibliotecas das escolas municipais de Belo Horizonte. 2010. Dissertação (Mestrado em Ciência da Informação) Escola de Ciência da Informação, Universidade Federal de Minas Gerais, Belo Horizonte, 2010.

PIERUCCINI, I. A ordem informacional dialógica: estudo sobre a busca de informação em Educação. 2004. 232 f. Tese (Doutorado em Ciência da Informação e Documentação) - Escola de Comunicação e Artes, Universidade de São Paulo, São Paulo, 2004.

PINHEIRO, M. I. S.; OLIVEIRA, J. A. V. Biblioteca escolar e a informática educativa. In: SEMINÁRIO BIBLIOTECA ESCOLAR ESPAÇO DE AÇÃO PEDAGÓGICA, 3., 2004, Belo Horizonte. Anais... Belo Horizonte, 2005. p. 212-227.

TARGINO, M. G. A biblioteca na concepção de escolares: influência de variáveis do ambiente escolar.1983. 187 f. Dissertação (Mestrado em Biblioteconomia) - Centro de Ciências Sociais Aplicadas, Universidade Federal da Paraíba, João Pessoa, 1983.

VILELA, R. M. Biblioteca escolar e EJA: caminhos e descaminhos. 141 f. Dissertação (Mestrado em Ciência da Informação) - Programa de Pós-Graduação em Ciência da Informação. Escola de Ciência da Informação da Universidade Federal de Minas Gerais, Belo Horizonte, 2009.

\section{Categoria: bibliotecário/professor ( 8 relatos)}

ALVES, M. C. A integração entre bibliotecário - professor no Brasil: o estado da arte. $1992.105 \mathrm{f}$. Dissertação (Mestrado em Biblioteconomia) - Pontifícia Universidade Católica de Campinas, Faculdade de Biblioteconomia, Campinas, 1992.

BESSA, A. Q. A interação entre bibliotecárias e professores de escolas públicas estaduais em Manaus, Amazonas, na biblioteca escolar. 2011. 220 f. Dissertação (Mestrado em Ciência da Informação) - Programa de Pós-Graduação em Ciência da Informação, Universidade Federal de Santa Catarina, Florianópolis, 2011. 
CARNEIRO, W. A utilização da biblioteca escolar como recurso de ensino-aprendizagem em livros de didática. 1991. 131 f. Dissertação (Mestrado em Educação) - Faculdade de Educação, Universidade Federal Fluminense, Niterói, 1991.

CORRÊA, E. C. D.; SOUZA, M. R. Parceria entre bibliotecário e educador: uma importante estratégia para o futuro da biblioteca escolar. In: SEMINÁRIO BIBLIOTECA ESCOLAR ESPAÇO DE AÇÃO PEDAGÓGICA, 3., 2004, Belo Horizonte. Anais... Belo Horizonte, 2005. p. 297 - 319.

GUEDES, C. A.; FARIAS, G. Informationliteracy: uma análise nas bibliotecas escolares da rede privada em Natal / RN. Revista Digital de Biblioteconomia e Ciência da Informação, Campinas, v. 4, n. 2, p. 110-133, 2007.

OLIVEIRA, H. V. Bibliotecas escolares e o planejamento educativo em escolas públicas de Brasília DF. 1999. 133 f. Dissertação (Mestrado em Ciência da Informação) - Departamento de Ciência da Informação e Documentação, Universidade de Brasília, Brasília, 1999.

SILVA, V. A. P. Proposta de integração entre educador e bibliotecário nas escolas de $1^{\circ}$ e $2^{2}$ graus. 1984. 101 f. Dissertação (Mestrado em Biblioteconomia) - Curso de Pós-Graduação em Biblioteconomia, Pontifícia Universidade Católica de Campinas, Campinas, 1984.

SILVA, M. A. Biblioteca escolar e professor: duas faces da mesma moeda: Investigação sobre a interação entre a biblioteca escolar e o professor do ensino fundamental na Rede Municipal de Ensino de Belo Horizonte. 2001. 149 f. Dissertação (Mestrado em Ciência da Informação) Escola de Ciência da Informação, Universidade Federal de Minas Gerais, Belo Horizonte, 2001.

\section{Categoria: Estudos de usos e usuários (13 relatos)}

CALDEIRA, P. T. et al. Uso de fontes de informação em bibliotecas escolares do 2º grau em Belo Horizonte, Minas Gerais. In: CONGRESSO BRASILEIRO DE BIBLIOTECONOMIA E DOCUMENTAÇÃO, 16., 1991, Salvador. Anais... Salvador: Associação Profissional dos Bibliotecários do Estado da Bahia, 1991. p. 274-293.

CAMPELLO, B. S. et al. A internet na pesquisa escolar: um panorama do uso da web por alunos do ensino fundamental. In: CONGRESSO BRASILEIRO DE BIBLIOTECONOMIA E DOCUMENTAÇÃO, 19., 2000, Porto Alegre. Anais ... Porto Alegre: Associação Rio Grandense de Bibliotecários, 2000. CD-ROM.

CAMPELLO, B. S.; ANDRADE, M. E. A.; MEDEIROS, N. L. A utilização de enciclopédias em bibliotecas públicas e escolares na região metropolitana de Belo Horizonte: relato de pesquisa. Ciência da Informação, Brasília, v. 22, n. 3, p. 259-262, 1993.

CARVALHO, L. S. Biblioteca escolar na rede adventista: um estudo de correlação entre infraestrutura e uso. 1998. 126 f. Dissertação (Mestrado em Biblioteconomia) - Pontifícia Universidade Católica de Campinas, Campinas, 1998.

DUMONT, M. M. V. Bibliotecas escolares comunitárias da Secretaria de Estado de Educação de Minas Gerais: análise de seu funcionamento em dez escolas de primeiro grau de Belo Horizonte. 1983. Dissertação (Mestrado em Administração de Bibliotecas) - Universidade Federal de Minas Gerais, Belo Horizonte, 1983. 
ELY, N. H. Indicadores de uso da biblioteca escolar em escolas públicas estaduais do ensino fundamental na cidade de Porto Alegre, RS, Brasil. In: CONGRESSO BRASILEIRO DE BIBLIOTECONOMIA, DOCUMENTAÇ̃̃O E CIÊNCIA DA INFORMAÇ̃̃O, 21., 2005, Curitiba. Anais...Curitiba: Associação Bibliotecária do Paraná, FEBAB, 2005.

GARCEZ, E. F. Avaliação de uso como indicador para a gestão da biblioteca escolar: estudo de caso. Revista ACB: Biblioteconomia em Santa Catarina, Florianópolis, v.12, n. 1, p. 59-73, 2007.

GOMES, J. F. Biblioteca escolar: estudo do perfil dos usuários da biblioteca Abelardo Hora do Colégio Marista Pio X. In: SEMINÁRIO BIBLIOTECA ESCOLAR ESPAÇO DE AÇÃO PEDAGÓGICA, 3., 2004, Belo Horizonte. Anais... Belo Horizonte, 2005. p. 170-195.

LEME, R. T. S. et al. A biblioteca infanto-juvenil como alicerce do futuro usuário das bibliotecas públicas e universitárias. In: CONGRESSO BRASILEIRO DE BIBLIOTECONOMIA E DOCUMENTAÇÃo, 11., 1982, João Pessoa. Anais... João Pessoa: Associação Profissional dos Bibliotecários da Paraíba, 1982. p. 95-115.

MATTOS, C. R. Mecanismos de busca da informação entre usuários do Curso Supletivo de $2^{\circ}$ Grau em Salvador. In: CONGRESSO BRASILEIRO DE BIBLIOTECONOMIA E DOCUMENTAÇÃO, 16., 1991, Salvador. Anais... Salvador: Associação dos Profissionais Bibliotecários do Estado da Bahia, 1991. p. 344-353.

PEREIRA, R. Aplicação da competência em informação no contexto escolar: uma experiência no Colégio Militar de Campo Grande - MS. 2010. 228 f. Dissertação (Mestrado em Ciência da Informação) - Universidade Estadual Paulista, Faculdade de Filosofia e Ciências, Marília, 2010.

PINHEIRO, M. I. S.; SILVA, V. C. Estudo de uso: uma análise da utilização das fontes de informação nas bibliotecas escolares públicas e privadas de Rondonópolis. In: SEMINÁRIO BIBLIOTECA ESCOLAR ESPAÇO DE AÇÃO PEDAGÓGICA, 3., 2004, Belo Horizonte. Anais... Belo Horizonte, 2005. p. 159-169.

SCHEFFER, E. M. K.; MORO, E. L. S.; MORIGI, V. J. Fortalecendo elos, transformando cidadãos: as relações entre a biblioteca escolar e a comunidade, um estudo na biblioteca Lourenço Filho em Porto Alegre - RS. In: CONGRESSO BRASILEIRO DE BIBLIOTECONOMIA, DOCUMENTAÇÃO E CIÊNCIA DA INFORMAÇÃO, 20., 2002, Fortaleza. Anais... Fortaleza, 2002.

\section{Categoria: Coleção (6 relatos)}

ELY, N. H. Biblioteca escolar em escolas públicas estaduais de 1o grau: um estudo sobre a atualização, adequação e utilização da coleção de livros. 1988. 163 f. Dissertação (Mestrado em Educação) - Faculdade de Educação, Pontifícia Universidade Católica do Rio Grande do Sul, Porto Alegre, 1988.

MAYRINK, P. T.; MORANDIN, R. H.; VINALLI, T. R. Avaliação de coleções da FDE em bibliotecas de escolas da região de Marília. R. Bras. Bibliotecon. e Doc., São Paulo, v. 25, n. 3/4, p. 49-59, jul./dez. 1992.

CAMPELLO, B. S. et al. Recursos informacionais para o ensino fundamental.Ciência da Informação, Brasília, v. 27, n. 3, p. 268-275, 1998. 
CAMPELLO, B. S. et al. Recursos informacionais em bibliotecas escolares: um estudo em bibliotecas de Belo Horizonte - MG. In: CONGRESSO BRASILEIRO DE BIBLIOTECONOMIA E DOCUMENTAÇÃO, 19., 2000, Porto Alegre. Anais... Porto Alegre, 2000.

CAMPELLO, B. S. et al.A coleção da biblioteca escolar na perspectiva dos Parâmetros Curriculares Nacionais. Informação\&Informação,v. 6, n.2, p. 71-88, jul./dez. 2001.

ABREU, V. L.F. G. et al. Diagnóstico das bibliotecas escolares da Rede Estadual de Ensino de Belo Horizonte - MG: a situação dos acervos. Enc. Bibli: R. Eletr. Bibliotecon. Ci. Inf., Florianópolis, n. 17, p. 19-33, 1‥ sem. 2004.

\section{Categoria: Leitura (17 relatos)}

ALONSO, C. M. R. Biblioteca escolar: um espaço necessário para leitura na escola. 2007.143 f. Dissertação (Mestrado em Educação) - Universidade Federal de São Paulo, São Paulo, 2007.

BERNARDES, A. S. O papel da biblioteca escolar na formação do sujeito leitor-escritor. 2003. $155 \mathrm{f}$. Dissertação (Mestrado em Educação) - Universidade Federal de Juiz de Fora, Juiz de Fora, 2003.

BORBA, M. S. A. et al. O desenvolvimento da leitura em bibliotecas escolares na cidade de NatalRN. In: CONGRESSO BRASILEIRO DE BIBLIOTECONOMIA, DOCUMENTAÇÃO E CIÊNCIA DA INFORMAÇÃO, 20., 2002, Fortaleza. Anais... Fortaleza: Associação dos Bibliotecários do Ceará, 2002. CD-ROM.

BORBA, M. S. A. Interesses de leitura de adolescentes: a contribuição da escola e da biblioteca. 1992. Dissertação (Mestrado em Ciência da Informação) - Pontifícia Universidade Católica de Campinas, Campinas, 1992.

BORBA, M. S. A. Adolescência e leitura: a contribuição da escola e da biblioteca escolar. In: CONGRESSO BRASILEIRO DE BIBLIOTECONOMIA E DOCUMENTAÇÃO, 19., 2000, Porto Alegre. Anais... Porto Alegre: Associação Rio-Grandense de Biblioteconomia, 2000. CD-ROM.

CARVALHO, A. M. S.; PONTES, R. B. Possíveis mediações para uma cultura biblioteconômica fundada nas teorias sociointeracionistas. In: CONGRESSO NACIONAL DE BIBLIOTECÁRIOS, ARQUIVISTAS E DOCUMENTALISTAS, 8., 2005, Lisboa. Anais...Lisboa: Associação Portuguesa de Bibliotecários, Arquivistas e Documentalistas, 2005.

DIOS, C. M. L. A dinamização da leitura na biblioteca escolar. 1989. 110 f. Dissertação (Mestrado em Educação) - Centro de Estudos Sociais Aplicados, Universidade Federal Fluminense, Niterói, 1989.

LIMA, L. F; PINHEIRO, M. I. S. Importância da biblioteca e do bibliotecário escolar para despertar o gosto pela leitura das crianças. In: CONGRESSO BRASILEIRO DE BIBLIOTECONOMIA, DOCUMENTAÇÃO E CIÊNCIA DA INFORMAÇÃO, 21., 2005, Curitiba. [Anais]. Curitiba: Associação Bibliotecária do Paraná, FEBAB, 2005. CD-ROM

MAGALHÃES, M. H. A. Uma leitura ...da leitura na escola de primeiro grau. 1992.196 f. Tese (Doutorado em Educação) - Faculdade de Educação, Universidade de São Paulo, São Paulo, 1992. 
MAGALHÃES, M. H. A. Leitura recreativa na escola de $1^{\circ}$ grau da rede oficial municipal de ensino de Belo Horizonte. 1980. 117 f. Dissertação (Mestrado em Administração de Bibliotecas) - Escola de Biblioteconomia, Universidade Federal de Minas Gerais, Belo Horizonte, 1980.

MARTUCCI, E. M.; CASSIAVILANI, C. Leitura de gibis no recreio: investigando a leitura de alunos de ensino fundamental em tempo livre. In: CONGRESSO BRASILEIRO DE BIBLIOTECONOMIA E DOCUMENTAÇÃO, 19., 2000, Porto Alegre. Anais... Porto Alegre: Associação Rio-Grandense de Bibliotecários, 2000.

MORO, E. L. S.; SOUTO, G. P.; ESTABEL, L. B. A influência da Internet nos hábitos de leitura do adolescente. In: SEMINÁRIO BIBLIOTECA ESCOLAR ESPAÇO DE AÇÃO PEDAGÓGICA, 3., 2004, Belo Horizonte. 2005. Anais... Belo Horizonte, 2005. p. 196-211.

SILVA, A. K. A. Ciência da informação e educação: ressignificando a formação de cidadãosleitores: discursos e práticas. In: ENCONTRO NACIONAL DE PESQUISA EM CIÊNCIA DA INFORMAÇÃO, 5., 2003, Belo Horizonte. Anais... Belo Horizonte, 2003. CD-ROM

SILVA, M. C. F. Formação de indivíduos leitores entre a biblioteca escolar, a família e outros apelos socioculturais. 2006. 198 f. Dissertação (Mestrado em Educação) - Universidade Federal de Minas Gerais, Faculdade de Educação, Belo Horizonte, 2006.

SILVA, S. A. Práticas e possibilidades de leitura na escola. 1997. 208 f. Dissertação (Mestrado em Educação) - Faculdade de Educação, Universidade Federal de Minas Gerais, Belo Horizonte, 1997.

SOUSA, M. I. J. Olhares entrecruzados: prática da leitura na escola e na biblioteca do Centro Educacional Carneiro Ribeiro. 2007. Tese (Doutorado em Educação) - Universidade Federal da Bahia, Salvador, 2007.

SOUSA, M. I. J. Espaço de práticas informacionais: a experiência da Biblioteca da Escola-Parque, projeto de Anísio Teixeira em Salvador, década de 60. 2001. Dissertação (Mestrado em Ciência da Informação) - Universidade Federal da Paraíba, João Pessoa, 2001.

\section{Categoria: Pesquisa escolar (15 relatos)}

ABE, V. A busca de informação na internet: bibliotecários e estudantes de Ensino Médio de escolas particulares de Itajaí e Florianópolis. 2009. Dissertação - (Mestrado em Ciência da Informação). Programa de Pós-Graduação em Ciência da Informação do Centro de Ciências da Educação da Universidade Federal de Santa Catarina, Florianópolis, 2009.

BIANCARDI, A. M. R.; GONÇALVES, A. C.; ESPÍRITO SANTO, E. L. A pesquisa escolar em tempo de transição: estudo de caso. In: CONGRESSO BRASILEIRO DE BIBLIOTECONOMIA E DOCUMENTAÇÃO, 19., Porto Alegre. Anais ... Porto Alegre: 2000.

BICHERI, A. L. A. O. Mediação do bibliotecário na pesquisa escolar face a crescente virtualização da informação. 2008. 197 f. Dissertação (Mestrado em Ciência da Informação) - Faculdade de Filosofia e Ciências, Universidade Estadual Paulista - UNESP, Marília, 2008.

CAMPELLO, B. S. et al. Aprendizagem pela pesquisa: busca e uso de informações na produção de conhecimento. In: ENCONTRO NACIONAL DE PESQUISA EM CIÊNCIA DA INFORMAÇÃO, 11., 2010, Rio de Janeiro. Anais... Rio de Janeiro, 2010. 
CASTRO, C. A.; SOUZA, M. C. P. Pedagogia de projetos na biblioteca escolar: proposta de um modelo para o processo da pesquisa escolar. Perspectivas em Ciência da Informação, v. 13, n. 1, p. 134-151, 2008.

FAQUETI, M. F. O bibliotecário como sujeito ativo no processo de ensino-aprendizagem através da pesquisa escolar: proposta de um modelo. 2002. 137 f. Dissertação (Mestrado em Engenharia de Produção) - Programa de Pós-Graduação em Engenharia de Produção, Universidade Federal de Santa Catarina, Florianópolis, 2002.

FIALHO, J. F. A formação do pesquisador juvenil: um estudo sob o enfoque da competência informacional. 2004. 131 f. Dissertação (Mestrado em Ciência da Informação) - Programa de Pós-Graduação em Ciência da Informação, Universidade Federal de Minas Gerais, Escola de Ciência da Informação, Belo Horizonte, 2004.

GARCEZ, E. F. Pesquisa escolar na educação básica: discurso de bibliotecários catarinenses. 2009. Dissertação (Mestrado em Ciência da Informação) - Programa de Pós-Graduação em Ciência da Informação, Centro de Ciências da Educação, Universidade Federal de Santa Catarina, Florianópolis, 2009.

MACHADO, A. M. N. Pesquisa escolar: uma questão para resolver. 92 f. 1989. Dissertação (Mestrado em Biblioteconomia) - Faculdade de Biblioteconomia, Pontifícia Universidade Católica de Campinas, Campinas, 1989.

MARTUCCI, E. M. Processo educativo na mediação da informação em biblioteca pública: um estudo fenomenológico. Revista de Biblioteconomia de Brasília, Brasília, v. 21, n. 2, p. 167-187, 1997.

NEUNZIG, V. L. A pesquisa escolar como elemento integrador dos recursos de biblioteca, Internet e sala de aula para a construção do conhecimento. 2004. Dissertação (Mestrado em Engenharia de Produção) - Universidade Federal de Santa Catarina, Florianópolis, 2004.

NEVES, I. C. B. Pesquisa escolar nas séries iniciais do ensino fundamental: bases para um desempenho interativo entre sala de aula e biblioteca escolar. 2000. $177 \mathrm{f}$. Tese (Doutorado em Ciência da Informação e Documentação) - Escola de Comunicações e Artes, Universidade de São Paulo, São Paulo, 2000.

OLIVEIRA, S. M. M.; MORENO, N. A.; CRUZ, V. A. G. Diagnóstico da pesquisa escolar no ensino de $5^{\underline{a}}$ a $8^{\underline{a}}$ série do $1^{\circ}$ grau, nas escolas de Londrina-Paraná. Informação\&Informação, Londrina, v. 4, n. 1, p. 37-50, jan./jun. 1999.

PÉCORA, G. M. M. Pesquisa na biblioteca escolar: a eficiência de um roteiro. 1998. $153 \mathrm{f}$. Dissertação (Mestrado em Biblioteconomia) - Curso de Pós-Graduação em Biblioteconomia, Pontifícia Universidade Católica de Campinas, Campinas, 1998.

PEREIRA, S. S. Biblioteca escolar e a orientação à pesquisa bibliográfica: a situação na rede pública de ensino.In: SEMINÁRIO BIBLIOTECA ESCOLAR ESPAÇO DE AÇÃO PEDAGÓGICA, 3., 2004, Belo Horizonte. Trabalhos apresentados... Belo Horizonte: Grupo de Estudos em Biblioteca Escolar, Escola de Ciência da Informação da UFMG, Associação dos Bibliotecários de Minas Gerais, 2004. 
